\title{
Study of Surface Plasmon Resonance of Gold Nanoparticles Stabilized by L-arginine
}

\author{
Amaria Amaria*, Dina K Maharani, and Maria M. Sianita \\ Department of Chemistry, Faculty of Mathematics and Natural Sciences, \\ Universitas Negeri Surabaya, Jl. Ketintang, Surabaya 60231, Indonesia \\ *) Corresponding author: amaria@unesa.ac.id
}

\begin{abstract}
Gold nanoparticles (AuNP) capped by L-arginine have been synthesized. In this paper, we report the stability of nanoparticles observed for six weeks. In this study, gold nanoparticles were synthesized by reducing $\mathrm{Au}(\mathrm{III})$ to $\mathrm{Au}(0)$ using trisodium citrate and capping agent L-arginine as a stabilizer. The parameters of this study are the $\mathrm{pH}$ of the medium $(5$ and 10$)$ and the concentration of-arginine $(1,2$, and $5 \mathrm{mM})$. The stability of gold nanoparticles was studied from the position of the maximum wavelength intensity of the full-width half-maximum absorption from the surface plasmon resonance spectra measured by UV-vis spectrophotometer. The results showed that gold nanoparticles were successfully synthesized by the appearance of a ruby red solution. The spectra of surface plasmon resonance AuNP-arg $\mathrm{pH}$ 10 shows sharper than $\mathrm{pH}$ 5. Gold nanoparticles (AuNP) can be stabilized using L-arginine at concentrations of 1-2.5 mM under $\mathrm{pH}$ 10. AuNP stabilized amino acid L-arginine was shown for a period of six weeks through the study of position changes of $\lambda_{\max }$, peak intensity and a full-width half-maximum of surface resonance plasmon spectra. These results prove that AuNP-arg can be used in commercial applications, as sensors or in the medical and cosmetic fields.
\end{abstract}

Keywords—gold nanoparticles, L-arginine, $A u(I I I)$ ion, stability

\section{INTRODUCTION}

Lately, the synthesis and characterization of gold nanoparticles have received much attention because of its application in various fields of science and technology. Gold nanoparticles (AuNP) is a material that is considered small, but in their synthesis, are likely to be larger aggregates. Efforts are made to avoid the replacement of aggregation is by releasing molecules coating or stabilizer (1)

The most common method for making dispersions of gold nanoparticles is the reduction of $\mathrm{Au}$ (III) by reducing agents such as sodium citrate and sodium borohydride in solvents. Dispersion of water-soluble gold nanoparticles has an important ability after capping with functional groups such as amino (2). Gold nanoparticles capped by aminofunctional groups of a certain size and shape are expressed as bifunctional nanoparticles.

Surface modification of gold nanoparticles with functional groups plays an important role in various applications, such as for organic, sensor and biodiagnostic reactions and drug delivery. Although surface modification of AuNP is generally associated with thiol and amino groups have been recognized to be strongly bonded with AuNP (3-5). For example, amino acids as naturally occurring amine groups are preferred over other amine groups. Zare et al $(6,7)$ reported the successful production of AuNP that can be dispersed in water with the L-arginine and glutamic acid in conjugating biomolecular.
Studies on the stability of AuNP have been widely publicized, but the studies of AuNP that have been stabilized by the amino acid L-arginine has not been widely reported. Zarabi et al. (4) reported the AuNP synthesis and capping strategy using tryptophan, glutamic acid, and aspartame acid for 5 days, which was made through the reduction of $\mathrm{Au}$ (III) ions with these amino acids and stabilizers sodium dodecyl sulfate (SDS). Akhavan et al. (8) synthesized gold nanoparticles in one step and a simple procedure with gamma irradiation using a protein from bovine serum albumin as a stabilizer. AgNP stability studies with mhydroxybenzoic acid and p-hydroxybenzoic acid were studied from the maximum wavelength, absorption intensity, and absorption peak width from plasmonic nanoparticle spectra (6). In this study, we succeeded in synthesizing gold nanoparticles that are stabilized by the amino acid L-arginine through the reduction of tetrachloro aurate by trisodium citrate under acidic and basic conditions. The amino acid L-arginine has an amino group $\left(-\mathrm{NH}_{2}\right)$, carboxyl $(-\mathrm{COOH})$ and guanidine $\left(-\mathrm{NHCNHNH}_{2}\right)$. Under acidic conditions, the amino group will be protonated to $-\mathrm{NH}_{3}{ }^{+}$and at the basic $\mathrm{pH}$ of the carboxyl group $(-\mathrm{COOH})$ it will turn into a carboxylic anion $\left(-\mathrm{COO}^{-}\right)(9)$ These groups can act as stabilizers in the synthesis of gold nanoparticles (2). The purpose of this study was to study the effect of $\mathrm{pH}$ and the addition of the amino acid L-arginine in stabilizing AuNP. AuNP stability is observed from the position of the maximum wavelength, the absorption intensity, and full-width half maximum of the surface plasmon resonance spectra.

\section{METHODS}

\section{A. Material and Instrumentation}

The precious metal of gold was bought from Aneka Tambang company. The metal dissolved in aquaregia (cont. hydrochloric acid: cont. nitric acid=3:1). Trisodium citrate dehydrates, L-arginine, sodium hydroxide was obtained from Merck. Measurement properties of optic, surface plasmon resonance by using the instrument of UV-vis spectrophotometer (Shimadzu 1800), a $\mathrm{pH}$ meter ( $\mathrm{pH} /$ ion 510 Eutech Oacton), and magnetic stirrer.

\section{B. Preparation of gold nanoparticles (AuNP).}

A thousand ppm solution of chloroauric (III) is prepared by dissolving $1 \mathrm{~g}$ of pure gold into aquaregia, then diluted with aquademineral until a volume of $1 \mathrm{~L}$. This work is done in a fume hood because there is released toxic $\mathrm{NO}_{2}$ gas. $\mathrm{A}$ total of $180 \mathrm{ml}$ of water is boiled in a $400 \mathrm{~mL}$ glass beaker and added $0.4 \mathrm{~g}$ of trisodium citrate. The solution was homogenized, and then added $4 \mathrm{~mL}$ of $\mathrm{AuCl}_{4}^{-} 1000 \mathrm{ppm}$. Then the solution is stirred, while heated until the light 
yellow color $\mathrm{Au}(\mathrm{III})$ solution disappears until the blue solution appears and finally the red AuNP solution is obtained. The red AuNP solution obtained was put into a $200 \mathrm{~mL}$ volumetric flask, then the volume was adjusted by adding aquademinerals up to $200 \mathrm{~mL}$.

\section{Preparation of Arginine-gold nanoparticles (AuNP-Arg)}

AuNP-Arg is synthesized at $\mathrm{pH} 5$ and 10, by adjusting the $\mathrm{pH}$ after the AuNP solution is formed through procedure A. Adjusting the $\mathrm{pH}$ of the solution by giving a $0.1 \mathrm{M}$ solution of $\mathrm{NaOH}$ or $0.1 \mathrm{M} \mathrm{HCl}$. Then various concentrations of L-arginine (1 mM, $2.5 \mathrm{mM}$, and $5 \mathrm{mM})$ were added to $4 \mathrm{~mL}$ AuNP under conditions of $\mathrm{pH} 5$ and 10. This work was carried out duplo. Furthermore, the characteristics of AuNP-arg were measured by UV-Vis spectrophotometer (4).

\section{RESULTS}

\section{A. The synthesis of gold nanoparticles $(A u N P)$}

In this research AuNP synthesized by added $\mathrm{AuCl}_{4}{ }^{-}$gold solution into boiling sodium citrate solution. The change of color from yellow become blue and then ruby red. This shows that the solution $\mathrm{Au}(\mathrm{III})$ has changed to $\mathrm{Au}(0)$. After AuNP is synthesized, then characterization is done by the UV-Vis spectroscopy method. To obtain AuNP relatively stable, did not immediately arise sediment and changes color to purple, then synthesized AuNP was added by Larginine in a variety of medium $\mathrm{pH}$ and concentration. Fig 1 $\mathrm{a}-\mathrm{b}$ show the surface resonance plasmon spectra of AuNP at pH 5 and 10 with concentrations of L-arginine $1 \mathrm{mM}, 2.5$ $\mathrm{mM}$, and $5 \mathrm{mM}$. Fig. 1 shows that the effect of L-arginine toward AuNP at pH 5 and $\mathrm{pH} 10$ in the concentration $1 \mathrm{mM}$, $2.5 \mathrm{mM}$, and $5 \mathrm{mM}$ give lower absorption intensity than AuNP. In Fig.1 (a) the $\lambda_{\max }$ of AuNP pH 5 is $533 \mathrm{~nm}$. AuNP-arg for L-arginine is $1 \mathrm{mM}, 2.5 \mathrm{mM}, 5 \mathrm{mM}$, all of the same is $531 \mathrm{~nm}$. This value indicates a blue shift of the surface plasmon resonance spectra (SPR). The same thing has been reported by Sunatkari et al (10). This SPR shift can be related to differences in particle size (11). In Fig.1 (b) the $\lambda_{\max }$ of AuNP pH 10 is $523 \mathrm{~nm}$. In AuNP-arg with L-arginine concentration $1 \mathrm{mM}, 2.5 \mathrm{mM}$ and $5 \mathrm{mM}$ provide $\lambda_{\max }$ relatively similar, i.e $523 \mathrm{~nm}$. The peak absorption of AuNP and AuNP-Arg at $\mathrm{pH} 10$ shows sharper than $\mathrm{pH} 5$.

The behavior of AuNP-arg at $\mathrm{pH} 5$ gives protonation of the amine group $\left(-\mathrm{NH}_{2}\right)$ from $\mathrm{L}$-arginine to $-\mathrm{NH}_{3}{ }^{+}$, but at $\mathrm{pH} 10$ the amine group of $\mathrm{L}$-arginine is not protonated $(\mathrm{PI}=10.76)$ (9). Therefore, in acidic conditions ( $\mathrm{pH} 5)$, there will be electrostatic interactions between L-arginine with negatively charged AuNP. At pH 10 the amine group is not protonated. Based on the soft and hard basic acidic properties (12), that the amine group $\left(-\mathrm{NH}_{2}\right)$ is a good base for $\mathrm{Au}(0)$, so the interaction between the amine group and AuNP is proposed through the electron pair donors of the amine group to the AuNP (7).

\section{B. The stability of Gold Nanoparticles}

The stability of AuNP-arg can be observed from changes in the maximum wavelength, absorption intensity, and fullwidth half maximum (FWHM) of surface plasmon resonance spectra (13). Position changes of the $\lambda_{\max }$ of AuNP during measurements from 10 minutes to six weeks at $\mathrm{pH} 5$ (a) and pH 10 (b) are presented in Fig 2. In Fig. 2a, shows the changes of $\lambda_{\max }$ occur mostly in the addition of L-arginine 2.5 and $5 \mathrm{mM}$. The changes in $\lambda_{\max }$ were sharp after a reaction takes place between AuNP and L-arginine for 1 day until 6 weeks. On the addition of $1 \mathrm{mM}$ L-arginine to AuNP after 2 weeks, giving increases of $\lambda_{\max }$ gradually until the 6th week. Gold nanoparticles at the addition of L-arginine 2.5 and $5 \mathrm{mM}$ (AuNP-arg at $\mathrm{pH}$ 5) are relatively unstable because they are marked by a shift in absorbance peaks at maximum wavelengths, which are large. In addition, there are deposits of black and pink color changes to dark blue. Generally, for all AuNP-args at pH 5 from 1 day to 6 weeks give changes of $\lambda_{\max }$ in the range $532-555 \mathrm{~nm}$ is $11-23 \mathrm{~nm}$. Fig. $2 b$ shows that changes in $\lambda$ max occur in the range of $1-2$ $\mathrm{nm}(523$ to $525 \mathrm{~nm})$ by the addition of L-arginine $1,2.5$ and $5 \mathrm{mM}$ into AuNP pH 10. The changes of $\lambda_{\max }$ of AuNP-arg from the reaction time period of 10 minutes to 6 weeks are relatively much smaller than AuNP $\mathrm{pH}$ 5. Shifting in $\lambda_{\max }$ indicates there is a change in particle size $(10,14)$. In AuNP $\mathrm{pH} 10$ by the addition of $1 \mathrm{mM}$ L-arginine show stable $\left(\lambda_{\max }\right.$ constant) until the period of one day, after that, there is a relatively small shift. At $\mathrm{pH} 10$ AuNP-arg provides better stability than $\mathrm{pH}$ 5. It is because L-arginine at $\mathrm{pH} 10$ is not protonated and its PI is 10.56 (9), so it can bind to AuNP by involving free electron pairs of nitrogen atoms from $-\mathrm{NH}_{2}$. Furthermore. the interaction hetween $\mathrm{I}$-arginine with AuNP
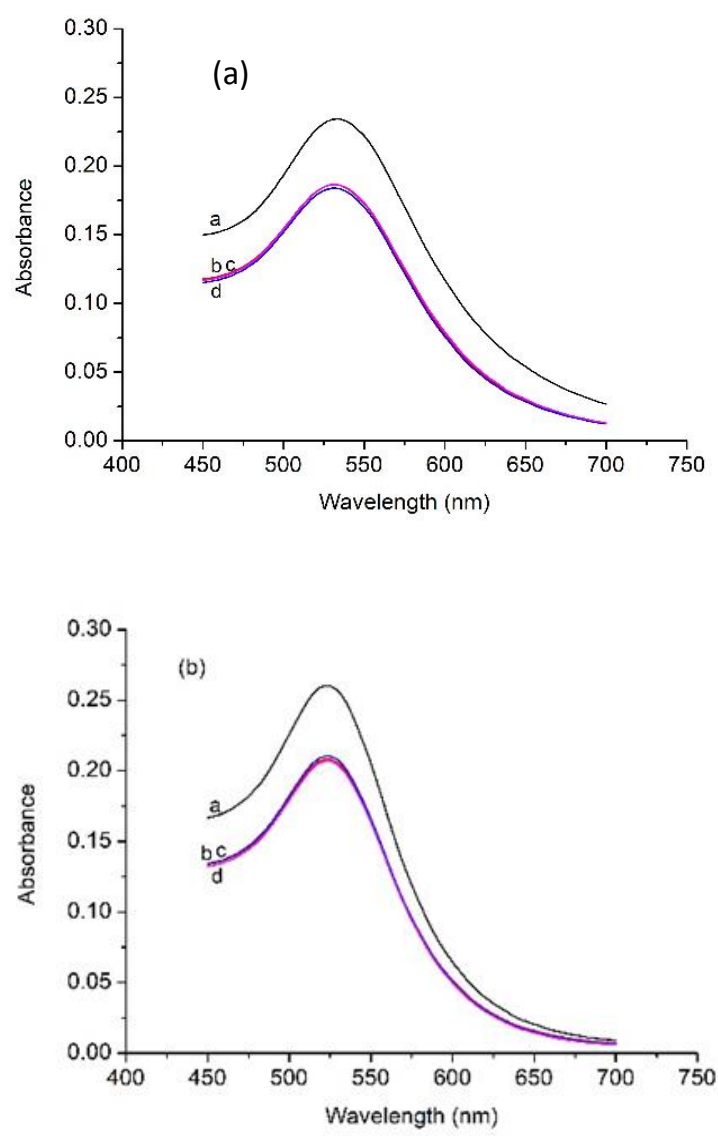

Fig.1 The surface resonance plasmon spectra of AuNP (curve a) and AuNP-Arg $1 \mathrm{mM}$ (curve b), AuNP-Arg $2.5 \mathrm{mM}$ (curve c), and AuNP-Arg 5 $\mathrm{mM}$ (curve d) at $\mathrm{pH} 5$ (a) and $\mathrm{pH} 10$ (b) 
The absorption peak intensity of AuNP-arg surface plasmon resonance is shown in Fig.3. Fig.3a (pH 5) shows that absorption peak intensity of AuNP-arg in a week storage time decreased by $8.6 \% ; 11.5 \%$ and $17.5 \%$ for L-arginine concentrations of $1 \mathrm{mM}, 2.5 \mathrm{mM}$, and $5 \mathrm{mM}$. This is like the observation of $\lambda_{\max } \mathrm{pH} 5$ reported above. After AuNP-arg is stored for 1-3 days there is an increase in absorption peak intensity, and in 1-6 weeks there is a decrease in absorption peak intensity. It is because agglomeration occurs. At $\mathrm{pH} 5$ the $-\mathrm{NH}_{2}$ group of L-arginine undergoes protonation to $\mathrm{NH}_{3}{ }^{+}$, which can interact ionically with $\mathrm{AuCl}_{4}^{-} / \mathrm{AuCl}_{2}{ }^{-}$from AuNP under acidic conditions (7).

Fig.3b (at $\mathrm{pH} 10$ ) shows that the absorption peak intensity up to 1 week, an increase in absorption peaks of $1-2 \%$ for concentrations of L-arginine 1 and $5 \mathrm{mM}$. When L-arginine concentration $2.5 \mathrm{mM}$, the intensity of AuNP-arg decreased by $1 \%$. Decreasing in absorption peak intensity is caused by a decrease in particle size or the dissolution of AuNP into Au ions $(13,15)$.

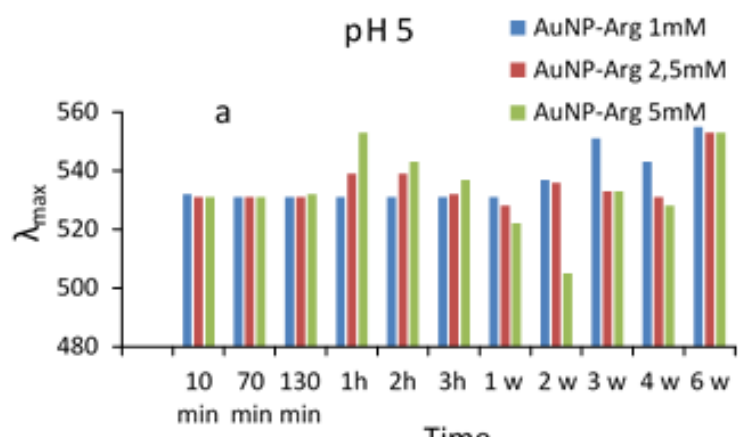

Time

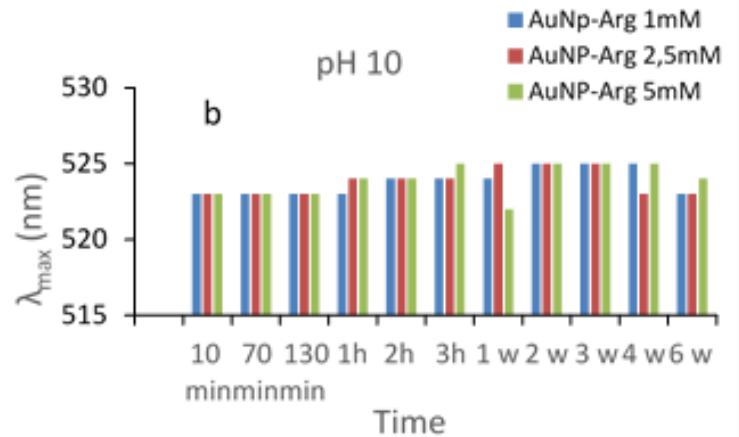

Fig. 2 Position changes of $\lambda_{\max }$ of gold nanoparticles in $10 \mathrm{~min}$ to six weeks at $\mathrm{pH} 5$ (a) and $\mathrm{pH} 10$ (b)
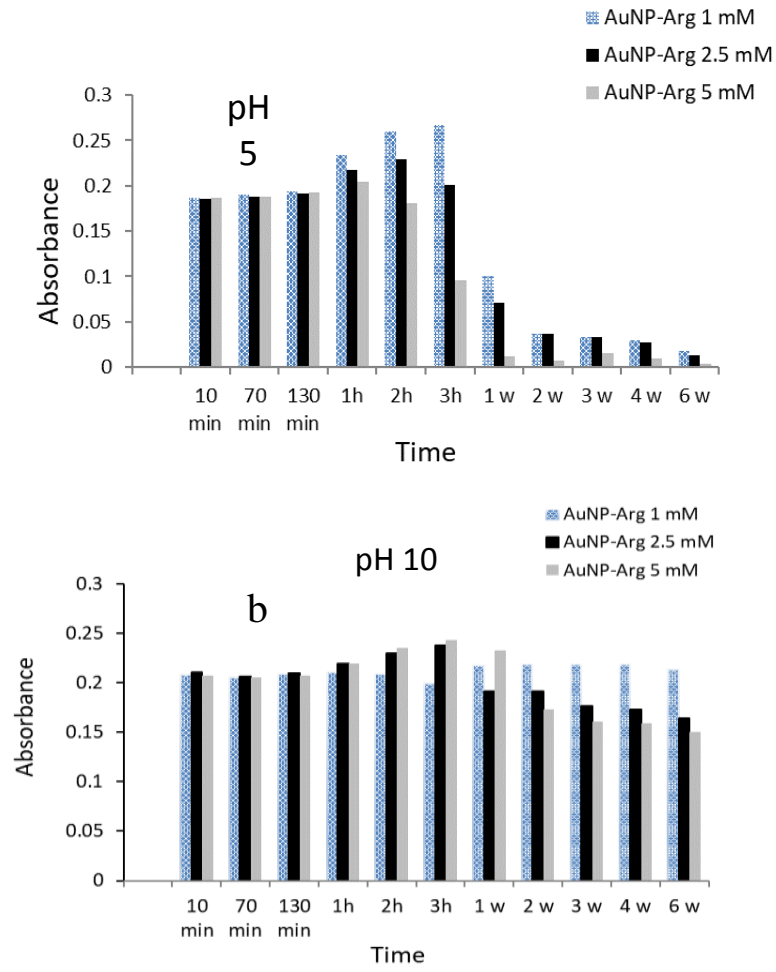

Fig.3 Position changes of the absorption peak intensity of gold nanoparticles in 10 min to six weeks at $\mathrm{pH} 5$ (a) and $\mathrm{pH} 10$ (b)

Fig.4 shows FWHM of AuNP-arg in conditions pH 5 and 10 for 6 weeks. FWHM data from absorption spectra can be an indicator of the monodispersity of gold nanoparticles. Small FWHM shows monodispersity, while large FWHM shows polydispersity (16). Oliveira et al. (16) report FWHM data from the absorption spectra of gold nanoparticles reduced by sodium citrate, ranging from 70.2 to $107.6 \mathrm{~nm}$. In this research, FWHM of AuNP-arg pH 5 (Fig.4a) was observed about $80 \mathrm{~nm}$ (at 10 to 130 minutes), and then after 1 day to a week gradually decreased to $60 \mathrm{~nm}$. Furthermore, after 2-6 weeks, it gradually increased to $140 \mathrm{~nm}$ (for AuNParg $1 \mathrm{mM}$ ). FWHM data of AuNP-arg at pH 10 (Fig.4b) was observed to be relatively constant $80 \mathrm{~nm}$. Based on the three types of characters from surface resonance plasmon spectra of AuNP, it can be stated that AuNP-arg at pH 10 with Larginine concentration 1-2.5 $\mathrm{mM}$ is more stable than $\mathrm{pH} 5$. 

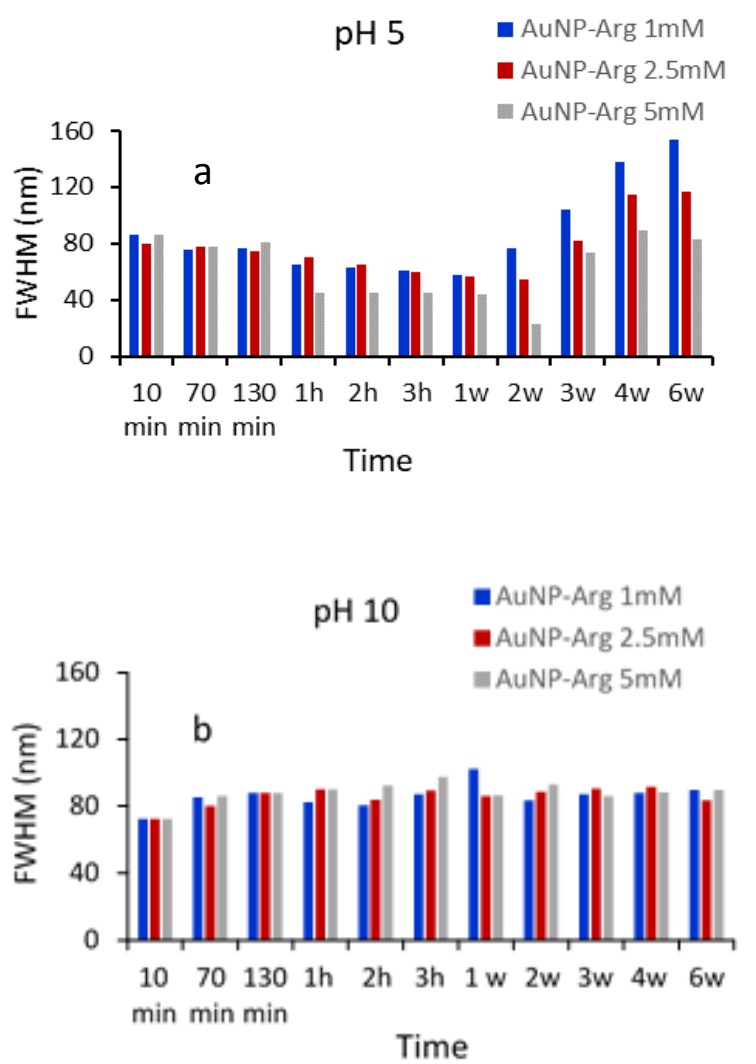

Fig. 4 Position changes of FWHM of gold nanoparticles in $10 \mathrm{~min}$ to six weeks at $\mathrm{pH} 5$ (a) and $\mathrm{pH} 10$ (b)

\section{CONCLUSION}

Gold nanoparticles (AuNP) can be stabilized using L-arginine at concentrations of 1-2.5 mM under $\mathrm{pH} 10$. AuNP was stabilized amino acid L-arginine shown for period six weeks through the study of position changes of $\lambda_{\max }$, absorption peak intensity and a full-width halfmaximum of surface resonance plasmon spectra. This shows that AuNP-arg can be used in commercial applications, as sensors or in the medical and cosmetic fields.

\section{ACKNOWLEDGMENT}

I would like to thank the Dean of FMIPA Universitas Negeri Surabaya for providing funds through BOPTN FMIPA Policy in 2019. I also thank Maya, Aprita, and Rojib for helping me in data collection.

\section{REFERENCES}

1. Rani M., Moudgil L, Singh B., Kaushal A., Mittal A., Saini G.S.S. Tripathi, S. K. Singh, G., Kaura, A., Understanding t.he mechanism of replacement of citrate from the surface of gold nanoparticles by amino acids: A theoretical and experimental investigation and their biological application. RSC Adv. 2016;6(21):17373-83.

2. Guerrini L., Alvarez-Puebla R.A., Pazos-Perez N. Surface modifications of nanoparticles for stability in biological fluids. Materials (Basel). 2018;11(7):1-28.

3. Zakaria H.M., Shah A., Konieczny M., Hoffmann J.A., Nijdam A.J., Reeves ME. Small molecule- and amino acid-induced aggregation of gold nanoparticles. Langmuir. 2013;29(25):7661-73.

4. Zarabi M.F., Arshadi N., Farhangi A., Akbarzadeh A. Preparation and characterization of gold nanoparticles with amino acids, examination of their stability. Indian J Clin Biochem. 2014;29(3):306-14.

5. Petean I., Tomoaia G., Horovitz O., Mocanu A., Tomoaia-Cotisel M.
Cysteine mediated assembly of gold nanoparticles. J Optoelectron Adv Mater. 2008;10(9):2289-92.

6. Zare D., Akbarzadeh A., Barkhi M., Khoshnevisan K., Bararpour N., Noruzi M., Tabatabaei, M. L-arginine and L-glutamic acid capped gold nanoparticles at physiological PH: Synthesis and characterization using agarose gel electrophoresis. Synth React Inorganic, Met Nano-Metal Chem. 2012;42(2):266-72.

7. Zare D., Akbarzadeh A., Bararpour N. Synthesis and Functionalization of Gold Nanoparticles by Using of Poly Functional Amino Acids. Int J Nanosci Nanotechnol. 2010;6(4):223-30.

8. Akhavan A., Kalhor H.R., Kassaee M.Z., Sheikh N., Hassanlou M. Radiation synthesis and characterization of protein stabilized gold nanoparticles. Chem Eng J. 2010;159(1-3):230-5.

9. Sridevi G. and Vani P. Kinetics and mechanism of oxidation of Larginine by sodium periodate in alkaline medium. Res J Pharm, Biol Chem Sci. 2010;1(4):977-86.

10. Sunatkari A.L., Talwatkar S.S., Tamgadge Y.S., Muley G.G. Synthesis Characterization and Optical Properties of L-Arginine Stabilized Gold Nanocolloids. Nanosci Nanotechnol. 2015;5(2):30-5.

11. Ojea-Jiménez I., Romero F.M., Bastús N.G., Puntes V. Small gold nanoparticles synthesized with sodium citrate and heavy water: Insights into the reaction mechanism. J Phys Chem C. 2010;114(4):1800-4.

12. Pearson R.G., Hard and Soft Acids and Bases, HSAB, Part I Fundamental principles. J Chem Educ. 1968;45(September):581-7.

13. Gusrizal G., Santosa S.J., Kunarti E.S., Rusdiarso B. Two Highly Stable Silver Nanoparticles: Surface Plasmon Resonance Spectra Study of Silver Nanoparticles Capped with m-Hydroxybenzoic Acid and pHydroxybenzoic Acid. Molekul. 2018;13(1):30.

14. Tomoaia G., Frangopol P.T., Horovitz O., Bobos L-D, Mocanu A., Tomoaia-Cotisel M. The Effect of Arginine on Gold Nanoparticles in Colloidal Solutions and in Thin Films. J Nanosci Nanotechnol 2011;11(9):7762-70.

15. Rodríguez-Fernández J., Pérez-Juste J., Mulvaney P., Liz-Marzán L.M., Luis M., Spatially-Directed Oxidation of Gold Nanoparticles by Au(III)-CTAB Complexes Jessica. J Phys Chem B Lett. 2005;109(30):14257-61.

16. Oliveira J.P., Prado A.R, Keijok W.J., Ribeiro M.R.N., Pontes M.J., Nogueira B.V., Guimarães, Marco C.C. A helpful method for controlled synthesis of monodisperse gold nanoparticles through response surface modeling. Arabian Journal of Chemistry. 2016; xxx, $\mathrm{xxX}-\mathrm{XXX}$ 